\title{
Cerambycidae (Coleoptera) coletados à luz a 45 metros de altura, no dossel da floresta amazônica, e a descrição de quatro espécies novas ${ }^{1}$
}

\author{
Ubirajara R. MARTINS',5, Maria Helena M. GALILEO ${ }^{3,5}$, Antonio SANTOS-SILVA², José Albertino \\ RAFAEL ${ }^{4,5}$ \\ RESUMO \\ É apresentada uma relação das 69 espécies de Cerambycidae coletados a $45 \mathrm{~m}$ numa torre metálica de $50 \mathrm{~m}$ que ultrapassa a maioria \\ das copas das árvores, num platô de terra firme, na bacia do Rio Cueiras, Estação Experimental de Silvicultura Tropical, km 14 do \\ núcleo ZF-2 em Manaus, Amazonas, Brasil. As coletas foram realizadas de janeiro a dezembro de 2004, durante três noites de \\ transição lunar minguante/nova de cada mês, das 18 às 6 horas. Os insetos foram capturados em um lençol iluminado com lâmpada \\ de 250 watts, luz mista de vapor de mecúrio e lâmpada de 20 watts BLB. Foram coletados Prioninae (12 espécies), Disteniinae (uma \\ espécie), Cerambycinae (27 espécies) e Lamiinae (29 espécies). Novas espécies descritas: Physopleurus rafaeli, sp. nov. (Prioninae, \\ Macrotomini); Oncideres tuberosa sp. nov. (Lamiinae, Onciderini), Plistonax rafaeli sp. nov. (Lamiinae, Acanthoderini) e Hemiloapis \\ mena sp. nov. (Lamiinae, Hemilophini). São apresentadas notas em Oncideres phaetusa Dillon \& Dillon, 1946, chave que modifica \\ aquela para as espécies de Physopleurus Lacordaire, 1869 e chave para as espécies de Hemiloapis Galileo \& Martins, 2004.
}

\section{PALAVRAS-CHAVE}

Coleta noturna, floresta amazônica, dossel, novas espécies, registros.

\section{Cerambycidae (Coleoptera) collected with light trap at 45 meters beight over an Amazon forest canopy and the description of four new species}

\begin{abstract}
A list of 69 species of Cerambycidae collected at $45 \mathrm{~m}$ height in a metallic tower of $50 \mathrm{~m}$ height, in a "platô de terra firme", in the Cueiras River basin, "Estação Experimental de Silvicultura Tropical, km 14 do núcleo ZF-2" in Manaus, Amazonas, Brazil. The collections were carried out monthly from January to December of 2004, during three nights of lunar transition third quarter monn/new moon from 18 p.m. to 6 a.m. The insects were collected over a vertical white sheet illuminated by a 250 watts mixed light and a 20 watts black-light (BLB) lamps. Were collected Prioninae (12 species), Disteniidae (one species), Cerambycinae (27 species) and Lamiinae (29 species). New species described: Physopleurus rafaeli, sp. nov. (Prioninae, Macrotomini); Oncideres tuberosa sp. nov. (Lamiinae, Onciderini), Plistonax rafaeli sp. nov. (Lamiinae, Acanthoderini) e Hemiloapis mena sp. nov. (Lamiinae, Hemilophini). Notes for Oncideres phaetusa Dillon \& Dillon, 1946, a modified key to the species of Physopleurus Lacordaire, 1869 and a key to the species of Hemiloapis Galileo \& Martins, 2004 are presented.
\end{abstract}

\section{KEY WORDS}

Amazonian forest; canopies; light collection; new species; records.

\footnotetext{
${ }_{1}^{1}$ Projeto “Biodiversidade de Arthropoda no manejo e conservação: um modelo amazônico", processo 472978/2003-9 financiado pelo Conselho Nacional de Desenvolvimento Cientifico e Tecnológico (CNPq).

${ }^{2}$ Museu de Zoologia, USP, São Paulo; Caixa Postal 42494, 04218-970. São Paulo, SP, Brasil.

${ }^{3}$ Museu de Ciências Naturais, Fundação Zoobotânica do Rio Grande do Sul, Caixa Postal 1188, 90001-970 Porto Alegre, RS, Brasil.

${ }^{4}$ Instituto Nacional de Pesquisas da Amazônia (INPA), Caixa Postal 478, 69011-970. Manaus, AM, Brasil.

${ }^{5}$ Pesquisador do CNPq.
} 


\section{INTRODUÇÃo}

Os Cerambycidae ocorrentes na Amazônia foram estudados por White $(1853 ; 1855)$ que descreveu várias espécies coletadas por Bates nas suas viagens pela Amazônia brasileira. Erichson (1847) descreveu os Cerambycidae da Amazônia Peruana. A maior contribuição sobre a família foi a de Bates (1861-1870) com a série "Contributions to an insect fauna of the Amazon Valley”. Aurivillius $(1891,1902,1908,1921)$ descreveu espécies do Peru, Bolívia e Brasil (região amazônica). As contribuiçōes posteriores, de vários autores, cuidaram da descrição e revisão de vários táxons.

Recentemente, Martins \& Galileo (2004) estudaram a fauna cerambicidológica da Venezuela amazônica presente nas copas de Matayba (Sapindaceae) e Vochysia (Vochysiaceae).

O trabalho está dividido em três partes: descrição do método de coleta e descrição florística por José Albertino Rafael, INPA, que participou das coletas e enviou o material para estudo; Prioninae e Disteniinae por Antonio Santos-Silva e Cerambycinae e Lamiinae por Ubirajara R. Martins e Maria Helena M. Galileo. São assinaladas as espécies identificadas e as espécies novas, descritas.

\section{MÉTODOS E COMPOSIÇÃO FLORÍSTICA}

Os cerambicídeos foram coletados à noite em floresta primária com armadilha luminosa (lençol branco iluminado com lâmpada de 250 watts, luz mista de vapor de mercúrio e lâmpada BLB) em nível superior ao da maioria das copas das árvores, a 45 metros de altura, em torre metálica de $6 \times 6 \mathrm{~m}$ de largura e $50 \mathrm{~m}$ de altura, localizada num platô de terra firme $\left(2^{\circ} 35^{\prime} 21^{\prime \prime S}\right.$, $\left.60^{\circ} 06{ }^{\prime} 55^{\prime \prime W}\right)$ na bacia do Rio Cueiras na Estação Experimental de Silvicultura Tropical do Instituto Nacional de Pesquisas da Amazônia (INPA), km 14 do núcleo ZF-2. As coletas foram realizadas mensalmente de $18 \mathrm{~h}$ às $6 \mathrm{~h}$, durante três noites, no período de transição lunar minguante/nova, nas noites mais escuras.

O material estudado está depositado no Instituto Nacional de Pesquisas da Amazônia (INPA) e no Museu de Zoologia da Universidade de São Paulo (MZSP).

O clima da região é do tipo Amw, segundo a classificação de Koppen, caracterizado como quente e úmido durante todo ano.

A composição florística foi realizada por Carneiro (2004) a cerca de cinco quilômetros da torre e é muito semelhante à existente nas proximidades. A composição em sete hectares de platô + baixio, considerando-se os indivíduos arbóreos de DAP (diâmetro à altura do peito) maior ou igual a $10 \mathrm{~cm}$ é de 737 espécies, pertencentes a 238 gêneros e a 59 famílias. As famílias mais ricas em espécies são: Sapotaceae (69 espécies), Chrysobalanaceae e Lauraceae (44), Lecythidaceae e Fabaceae (39) e Mimosaceae (38).
As espécies vegetais de maior importância econômica são: Oenocarpus batana Mart. (patuá), Eschweilera coriacea (DC) Mart. ex Berg. (matamatá-verdadeira), E. pseudodecolorans S.A.Mori (matamatá), E. truncata A.C.Sm. (matamatá), E. wachenheimii (Benoist) Sandwith (matamatá-mirim), Eperua glabrifolia (Ducke) R.S.Cowan, Hevea guaianensis Aubl. (seringueira), Scleronema micracanthum Ducke (cardeiro) e Vitex sprucei Briq.

No platô a composição florística é de 533 espécies pertencentes a 187 gêneros e 53 famílias, apresentando uma densidade total de $623 \mathrm{ind} /$ ha e área basal de $28,3 \mathrm{~m}^{2}$ ha- 1 . No baixio a composição florística é de 461 espécies pertencentes a 177 gêneros e 50 famílias, apresentando uma densidade total de $624 \mathrm{ind} / \mathrm{ha}$ e área basal de 29,1 $\mathrm{m}^{2}$ ha-1. Quanto à exclusividade de famílias, gêneros e espécies, o platô possui nove famílias, 60 gêneros e 281 espécies, enquanto que o baixio, seis famílias, 54 gêneros e 212 espécies.

\section{DISTENIINAE E PRIONINAE}

Foram coletadas 13 espécies.

\section{Disteniinae}

Disteniini

Distenia suturalis Bates, 1870 - ᄋ

\section{Prioninae}

Callipogonini

Ctenoscelis coeus (Perty, 1832) - o

Ctenoscelis ater (Olivier, 1795) - $\sigma^{7}$

Enoplocerus armillatus (Linnaeus, 1767) - 07 ,

Orthomegas similis Gahan, 1894 - 9

Orthomegas cinnamomeus (Linnaeus, 1758) - $0^{*}$

\section{Meroscelisini}

Hyleoza confusa Tavakilian \& Galileo, 1991 - o

\section{Macrotomini}

Mallodon spinibarbis (Linnaeus, 1758) - 5 ठే, 6 ㅇ

Ialyssus tuberculatus (Olivier, 1795) - $0^{*}$

Hisarai seripiierriae (Santos-Silva \& Martins, 2003) - o

Physopleurus crassidens (Bates, 1869) - 9

Physopleurus amazonicus (Fragoso \& Monné, 1995) - 2 o

\section{Physopleurus rafaeli Santos-Silva, sp. nov. (Figs. 1, 2)}

Etimologia. O epíteto é uma homenagem ao dipterólogo do INPA, José Albertino Rafael, que coletou e enviou o material para estudo.

Macho (Fig. 1). Tegumento castanho-escuro a preto; peças bucais de cor castanha. 
ACTA AMAZONICA
CERAMBYCIDAE (COLEOPTERA) COLETADOS À LUZ A 45 METROS DE ALTURA, NO DOSSEL

DA FLORESTA AMAZÔNICA, E A DESCRIÇÃO DE QUATRO ESPÉCIES NOVAS


Figuras 1-6 - Habitus. 1, 2, Physopleurus rafaeli Santos-Silva, sp. nov., respectivamente holótipo macho e parátipo fêmea; 3, Oncideres tuberosa Martins \& Galileo, sp. nov., holótipo macho; 4, 0. fabricii Thomson, 1868, macho; 5, Plistonax rafaeli Martins \& Galileo, sp. nov., holótipo macho; 6, Hemiloapis mena Martins \& Galileo, sp. nov., holótipo macho. 
Superfície dorsal da cabeça com pontos muito grossos, profundos e anastomosados, gradualmente mais finos e abundantes em direção ao occipício. Labro transversal, com os ângulos látero-apicais projetados e aguçados; ápice saliente e aguçado ou suavemente arredondado. Ápice das genas projetado e aguçado (um dos machos apresenta o ápice intumescido e arredondado, o que julgamos uma malformação). Área hipostomal com pontos rasos, grandes e anastomosados, exceto na região próxima ao mento, que é elevada e com pontos moderadamente finos e esparsos; pilosidade esparsa e longa. Lígula inteira. Distância entre os ápices das paraglossas cerca de cinco vezes menor do que a largura da cabeça. Segundo artículo dos palpos maxilares mais longo do que o terceiro. Mandíbulas com carena dorsal muito elevada da base até o terço apical; face interna com pêlos longos; margem interna com três dentes: dois dentes juntamente protraídos na metade apical; outro na metade basal (bífido em um dos machos); margem látero-externa fortemente intumescida no meio. Antenas ultrapassam o meio dos élitros; escapo ultrapassa a borda posterior do olho; antenômero III com cerca da metade do comprimento do escapo; antenômeros III-X subiguais em comprimento. Antenômero XI apenas mais longo do que o X.

Comprimento do protórax, no centro, cerca de 0,6 vez a maior largura. Bordas laterais do protórax crenadas, com espinho no terço basal; borda anterior suavemente côncava; cantos anteriores projetados e arredondados; disco com calosidade brilhante, larga no quarto basal, estreita no quarto seguinte $\mathrm{e}$ larga na metade apical; pontuação das calosidades moderadamente grossa e esparsa; pontuação entre as duas áreas largas da calosidade com pontuação muito grossa, anastomosada e mais rasa do que a pontuação da região lateral do pronoto; regiāo média do disco, ao lado das calosidades, com carena evidente; laterais do pronoto com pontuação muito grossa, anastomosada e profunda. Prosterno intumescido, com pontos grossos, profundos e moderadamente esparsos, mais grossos e bem marcados em direção aos proepimeros; pilosidade muito dispersa. Suturas prosternais, distintas apenas próximo aos ângulos anteriores do protórax. Proepisternos nulos. Metasterno liso e brilhante na região central; laterais e região anterior com pontos finos e abundantes, entremeados por pontos grossos; pilosidade curta e numerosa na área pontuada e esparsa na área lisa. Metepisternos com microasperezas e pilosidade igual à da área pontuada do metasterno. Élitros abundantemente pontuados, principalmente nos $3 / 4$ centrais; ápice elitral com espinho curto junto à sutura. Profêmures com raros espinhos curtos na face ventral. Tíbias com espinhos curtos na face ventral, os quais são mais numerosos nas protíbias do que nas mesotíbias e mais numerosos nessas do que nas metatíbias.

Fêmea (Fig. 2). Margem látero-externa das mandíbulas fracamente intumescida; margem interna com dois dentes. Antenas atingem apenas o terço basal dos élitros. Calosidade do pronoto sem o estreitamento acentuado próximo à base. Prosterno com pontos mais esparsos e rasos. Sutura prosternal marcada em toda extensão. Proepisternos estreitos.

Dimensōes em mm, respectivamente macho/fêmea. Comprimento total, 56,5-58,0/60,2-63,0; protórax: largura anterior, 11,4-12,0/11,0-12,0; largura entre os espinhos das margens laterais, 14,4-15,6/15,7-16,0; comprimento do pronoto no centro, 8,6-8,8/9,3-9,2; largura umeral, 14,8-16,0/17,018,0; comprimento elitral, 36,0-36,1/43,5-44,0.

Material-tipo. Holótipo macho, BRASIL, Amazonas: Manaus (Estrada ZF-2, km14, torre, $35 \mathrm{~m}$ de altitude, $02^{\circ} 35^{\prime} 21^{\prime \prime} \mathrm{S}$, 6006'55"W; lençol, luz mista e BLB), 10-13.XII.2004, C. S. Motta, A. S. Filho, S. Trovisco \& M. Cutrin col. (INPA).

Parátipos - BRASIL, Amazonas: (Estrada ZF-2, km14, torre, $35 \mathrm{~m}$ de altitude, $02^{\circ} 35^{\prime} 21^{\prime \prime} \mathrm{S}, 60^{\circ} 06^{\prime} 55^{\prime \prime} \mathrm{W}$; lençol, luz mista e BLB), macho, 12-15.X.2004, J. A. Rafael, C. S. Motta, F. F. Xavier Fo, A. Silva \& S. Trovisco col. (MZSP); 2 fêmeas, 912.XI.2004, C. S. Motta, A. S. Filho, S. Trovisco \& L. S. Aquilo col. (INPA, MZSP).

Discussão. É semelhante à $P$. crassidens (Bates, 1869) e $P$. exiguus Santos-Silva \& Martins, 2003. Difere de P. crassidens pela distância entre os lobos oculares superiores menor do que o comprimento do escapo e pela pontuação do disco do pronoto apenas mais fina. Em P. crassidens a distância entre os lobos oculares superiores é aproximadamente igual ao comprimento do escapo e a pontuação do disco do pronoto é mais grossa. É diferenciada de P. exiguus principalmente pela forma do pronoto, nitidamente mais largo do que a cabeça e com espinho nítido no terço posterior. Em P. exiguus o pronoto é pouco mais largo do que a cabeça e não há espinho nítido no terço posterior.

Difere ainda de P. dohrnii Lacordaire, 1869 pelas mandíbulas intumescidas na margem externa, pelo prosterno menos intumescido e pelos élitros nitidamente pontuados. P. dohrnii possui mandíbulas não intumescidas na face látero-externa, prosterno fortemente intumescido e élitros sublisos.

Na chave apresentada em Santos-Silva \& Martins (2003), P. rafaeli sp. nov. deve ser alocada a partir do dilema 3 (modificado): 3(2). Lados do prosterno dos machos visíveis em vista dorsal; margens laterais do protórax sem espinho nítido nos dois sexos. Bolivia (Santa Cruz); BRASIL (Mato Grosso)...... . . ............ P. exiguus Santos-Silva \& Martins, 2003

Lados do prosterno dos machos invisível em vista dorsal; margens laterais do protórax com espinho nítido nos dois sexos. .. . 4 4(3). Distância entre os lobos oculares superiores subigual ao comprimento do escapo. Brasil (Amazonas, Mato Grosso). . .................... P. crassidens (Bates, 1869)

Distância entre os lobos oculares superiores nitidamente menor do que o comprimento do escapo. Figs. 1-2. Brasil (Amazonas)............ P. rafaeli Santos-Silva sp. nov. 
CERAMBYCINAE E LAMIINAE

Foram coletadas 56 espécies.

Cerambycinae

Oemini

Malacopterus tenellus (Fabricius, 1801) - o, 2 \%

Neoeme annulicornis (Buquet, 1859) - 2 o

Achrysonini

Achryson pictum Bates, 1870 - §, 2 ㅇ

Cerambycini

Cerambycina

Atiaia consobrina (Gahan, 1892) - $3 \sigma^{*}$

Hirtobrasiliainus villiersi Fragoso \& Tavakilian, 1985-2 ot

Juiparus b. batus (Linnaeus, 1758) -2 o , 9

Plocaederus bipartitus (Buquet, 1860) - 3 ơ, 4 \%

Plocaederus plicatus (Olivier, 1795) - $0^{*}$

Sphallotrichina

Coleoxestia glabripennis (Bates, 1870) - o

Sphallotrichuspuncticollis (Bates, 1870) - $\odot$

Hesperophanini

Paraliostola durantoni Tavakilian \& Monné, 1991-6 đđ, 2 ᄋ

Eburiini

Beraba cauera Galileo \& Martins, 1999 - o"

Eburodacrys elegantula Gounelle, 1909 - o

Eburodacrys notula Gounelle, 1909 - ơ

\section{Elaphidionini}

Clausirion comptum Martins \& Napp, 1984-2 o

Mephritus auricolle Tavakilian \& Martins, 1991 - $\sigma^{*}$

Nephalius cassus (Newman, 1841) - 2 o, 2 \%

Periboeum pubescens (Olivier, 1790) - $\sigma^{*}$

\section{Ibidionini}

Compsibidion maronicum (Thomson, 1867) - o

Thoracibidion io (Thomson, 1867) - o

Thoracibidion ruficaudatum (Thomson, 1865) - 9

\section{Bothriospilini}

Chlorida festiva (Linnaeus, 1758) - o

Coccoderus longispinicornis Fuchs, 1964-2 o

Torneutini

Diploschema brunnea Martins \& Monné, 1980 - ơ

Gigantotrichoderes flabellicornis (Zajciw, 1965) -40

Gnathopraxithea sarryi Seabra \& Tavakilian, $1986-2$ o , o

Praxithea seabrai Tavakilian \& Monné, 2002 - 3 ơ, 2 ㅇ
Lamiinae

Onciderini

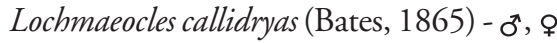

Oncideres fabricii Thomson, 1868 - (Fig. 4), ơ

Oncideres gemmata Dillon \& Dillon, 1946-2 $\sigma^{\pi}$, 우

Oncideres gutturator (Fabricius, 1775) - ठే, 2 \%

Oncideres nivea Dillon \& Dillon, 1946 - 2 o??

Oncideres voet $i$ Thomson, 1868 - $\sigma^{*}$

Pseudobeta ferruginea Galileo \& Martins, 1990 - o

Trachysomus peregrinus Thomson, 1868 - o

\section{Oncideres phaetusa Dillon \& Dillon, 1946}

Oncideres phaetusa Dillon \& Dillon, 1946: 338, est.13, fig. 5; Monné, 1994: 56 (cat.).

Dillon \& Dillon (1946) basearam a descrição em única fêmea, procedente do Brasil, Amazonas, Rio Purus, "Hyutanahan" ou atual Huitanaã. $\mathrm{O}$ macho apresenta alguns caracteres diferentes daqueles da fêmea: tubérculos anteníferos bem aguçados; antenômero III fortemente curvo; pronoto com três gibosidades dorsais glabras: duas látero-anteriores e uma centro basal; tubérculo umeral mais desenvolvido

Dimensões em mm, macho. Comprimento total, 12,4; comprimento do protórax, 3,1; maior largura do protórax, 4,3; comprimento do élitro, 11,1; largura umeral (tubérculo umeral inclusive), 6,9.

Material examinado. BRASIL, Amazonas: Manaus (Torre, ZF $2, \mathrm{~km} \mathrm{14}, 02^{\circ} 35^{\prime} 21^{\prime \prime S} 60^{\circ} 06^{\prime} 55^{\prime \prime} \mathrm{W}$, luz mista e BBL), macho, 18-21.II.2004, J. A. Rafael, C. S. Motta, F. F. Xavier Filho, A. Silva Fo \& S. Trovisco col. (INPA).

\section{Oncideres tuberosa Martins \& Galileo, sp. nov. (Fig. 3)}

Macho. Tegumento castanho-escuro e preto nos tubérculos dos élitros. Pubescência na face dorsal e nas pernas amarelada; nas antenas e na face ventral, esbranquiçada. Globos oculares inferiores com o triplo do comprimento das genas. Escapo gradualmente engrossado para o ápice. Antenômeros III e IV com densa franja de pêlos, mais curtos que a largura do artículo, no lado interno. Pronoto com faixa transversal, glabra, no meio. Espinho lateral do protórax aguçado. Quinto basal dos élitros com tubérculos grandes e muito próximos entre si, glabros e elíptico-arredondados. Metade anterior com manchas glabras moderadamente abundantes; no nível do terço apical as manchas estão mais próximas e constituem uma faixa transversal. Terço apical dos élitros com manchas glabras esparsas e duas linhas longitudinais indistintas.

Dimensões em mm, holótipo macho. Comprimento total, 19,9; comprimento do protórax, 3,5; maior largura do protórax, 6,5; comprimento do élitro, 15,0; largura umeral, 8,9. 
Material-tipo. Holótipo macho, BRASIL, Amazonas: Manaus (Torre, ZF 2, km 14, 02 $35^{\prime} 21^{\prime \prime S} 60^{\circ} 06^{\prime} 55^{\prime \prime W}$, luz mista e BBL), 21-24.I.2004, C. S. Motta, S. Trovisco, F. F. Xavier Fo \& A. Silva Fo col. (INPA).

Discussão. Oncideres tuberosa sp. nov. é semelhante à $O$. fabricii Thomson (Fig. 4), mas difere pela pubescência corporal amarelada; pelos pêlos da franja interna do antenômero III mais longos e abundantes; pelos tubérculos glabros maiores e distribuídos em área mais estreita na base dos élitros; pelas manchas glabras no meio dos élitros mais abundantes e maiores; pela ausência de pequenas manchas glabras no terço apical dos élitros. Em O. fabricii a pubescência corporal é esbranquiçada; a franja interna do antenômero III é mais curta e esparsa; os tubérculos glabros são menores e atingem o quarto anterior; manchas glabras são pequenas e esparsas; manchas glabras abundantes e concentradas no nível do terço apical.

É semelhante também a Oncideres cephalothes Bates 1865, mas é distinta pela pubescência corporal amarelada, pelos grânulos junto à base dos élitros que são maiores e em menor número; pelas manchas glabras dos élitros elípticas; pela ausência de faixas constituídas por manchas glabras. Em O. cephalothes, a pubescência corporal (menos a da cabeça) é branca; os grânulos junto à base dos élitros são menores e numerosos; as manchas glabras do meio dos élitros são longitudinais; no terço apical, faixa constituída por manchas glabras muito próximas.

Grânulos concentrados na base dos élitros também estão presentes em O. malleri Fragoso, 1970 e O. pretiosa Martins \& Galileo, 1990, contudo em O. pretiosa o terço apical dos élitros tem manchas alaranjadas e em $O$. malleri a base dos élitros tem pubescência alaranjada e pubescência branca no restante da superfície.

\section{Anisocerini}

Onychocerus albitarsis Pascoe, 1859 - 9

Onychocerus concentricus Pascoe, 1862 - ơ

\section{Acanthocinini}

Atrypanius conspersus (Germar, 1824) - $\sigma^{*}$

Lepturges glaphyra? Monné, 1976 - đ‘

Paroecus celebensis (Thomson, 1857) - $\sigma^{\star \top}$

Paroecus charpentieri Villiers, 1971 - $\sigma^{\circ}$

\section{Acanthoderini}

Oreodera glauca glauca (Linnaeus, 1758) - 2 ○

Oreodera tuberosa Monné \& Fragoso, 1988 - o

Ozotroctes punctatissimus Bates, 1861 - q

Psapharochrus spinicornis Tippmann, 1960 - 3 ठే, 2 \&
Plistonax albolinitus (Bates, 1861) - 2 o

Plistonax insolitus Monné, 2001 - o

Plistonax travassosi Monné \& Magno, 1992 - 2 ㅇ

Steirastoma genisspina Schwarzer, 1923-3 ơ, 2 ㅇ

Steirastoma melanogenys White, 1855 - o

\section{Plistonax rafaeli Martins \& Galileo, sp. nov. (Fig. 5)}

Etimologia. Epíteto homenageia o entomólogo do INPA José Albertino Rafael.

Macho. Tegumento castanho-avermelhado. Cabeça revestida por pubescência amarelada. Fronte com pontos profundos, muito esparsos. Antenas atingem os ápices dos élitros na extremidade do antenômero IX. Escapo com tufos de pêlos esbranquiçados em toda a superfície. Flagelômeros escurecidos nos ápices. Antenômeros III e IV com pincéis de pêlos esbranquiçados. Protórax com tubérculo lateral cônico. Pronoto com duas gibosidades ântero-laterais. Pubescência pronotal amarelada com uma faixa de pubescência preta larga da gibosidade até a base; pontuação escassa, pontos profundos e isolados. Processo mesosternal indistintamente bituberculado. Élitros revestidos por pubescência amarelada; cada um com áreas pretas: uma restrita aos úmeros, uma pequena, próxima da sutura, no sexto anterior, uma irregular, dorsal, que lembra uma letra $\mathrm{V}$, logo atrás do meio, uma mais transversal, estreita, no sexto apical; mancha pequena de pubescência branca dorsal antes do meio. Base dos élitros com curta elevação. Pontuação elitral abundante com setas curtas e brancas no interior dos pontos. Extremidades elitrais transversalmente truncadas com projeção curtíssima no lado externo. Fêmures com pincéis de pêlos brancos. Protarsos com pêlos pretos, laterais. Tarsômero I tão longo quanto II+III.

Dimensões em mm, holótipo macho. Comprimento total, 12,0; comprimento do protórax, 2,6; maior largura do protórax, 4,5; comprimento do élitro 8,2; largura umeral 5,2.

Material-tipo. Holótipo macho, BRASIL, Amazonas: Manaus (Torre 35m, ZF 2, km 14, 02³5’21"S 6006'55"W, luz mista e BBL), 13-16.IX.2004, F. F. Xavier Filho, A. R. Ururahy, F. Godoi \& S. Trovisco col. (INPA).

Discussão. O gênero Plistonax Thomson, 1864, foi tratado por Monné (2001) que apresentou chave para as espécies e descreveu $P$. insolitus. Nessa chave $P$. rafaeli pelas extremidades elitrais truncadas, corre para o item 2 e é mais semelhante a $P$. inopinatus Lane, 1950 e P. albolinitus (Bates, 1861), pelas escamas curtas, brancas, que emergem dos pontos. É distinta de ambas pelo padrão de colorido e extremidades dos élitros. Tanto em $P$. inopinatus como em P. albolinitus as extremidades dos élitros são arredondadas. 
Acrocinini

Acrocinus longimanus (Linnaeus, 1758) - o

Xenofreini

Xenofrea exotica Galileo \& Martins, 1999 - o*

Hemilophini

\section{Hemiloapis mena Martins \& Galileo, sp. nov. (Fig. 6)}

Etimologia. Tupi, mena = marido; alusivo a possibilidade de ser o sexo oposto de $H$. ybyra.

Macho. Semelhante a Hemiloapis ybyra (Galileo \& Martins, 2004: 387, fig. 8). Cabeça revestida por pubescência amarelada menos mancha preta em forma de "U" com prolongamento único, central, para o occipício. Região pós-ocular amarelada com mancha preta aparente apenas sob a borda anterior do pronoto. Desenho pronotal como em H. ybyra (Fig. 6), isto é, com faixas amareladas: uma, estreita, na orla anterior emite curto prolongamento no meio; duas curvas, interrompidas no meio; uma transversal, curta no meio da base; lados do terço basal do pronoto com mancha de pubescência amarelada separada por uma faixa estreita preta das partes laterais do protórax que são revestidas inteiramente por pubescência amarelada. Élitros com tegumento bicolor, a metade anterior como em H. ybyra (Fig. 6), isto é, com faixa de pubescência amarelada, irregular; a metade apical com três faixas estreitas de pubescência amarelada: uma ligeiramente recurva atrás do meio, a segunda perpendicular à sutura no quarto apical, a terceira curva em sentido oposto ao da primeira no sexto apical; as três faixas estão unidas entre si junto à margem. Metasterno com pubescência amarelada cobre área triangular, lateral. Urosternitos pretos com manchas laterais de pubescência branca.

Dimensões em mm, holótipo macho. Comprimento total, 8,8; comprimento do protórax, 1,7; maior largura do protórax, 2,3; comprimento do élitro, 6,0; largura umeral, 2,9.

Material-tipo. Holótipo macho, BRASIL, Amazonas: Manaus (Torre 35m, ZF2, km-14, $02^{\circ} 35^{\prime} 21^{\prime \prime S ~ 6006 ’ 5 ~ " W, ~ l u z ~ m i s t a ~}$ e BBL), 12-15.X.2004, J. A. Rafael, C. S. Motta, F. F. Xavier Fo, A. Silva Fo \& S. Trovisco col. (INPA).

Discussão. Hemiloapis mena sp. nov., baseada num macho, tem o mesmo padrão de colorido de $H$. ybyra conhecida pelo holótipo fêmea, exceto as faixas de pubescência amarelada dos élitros. $\mathrm{O}$ exame de material mais abundante poderá elucidar a possibilidade dessa diferença ser apenas sexual.

Chave para as espécies de Hemiloapis Galileo \& Martins, 2004

1. Pronoto com pubescência avermelhada e apenas os frisos anterior e posterior finamente cobertos por pubescência branco-amarelada; flagelômeros III-V pretos, VI-XI brancos; franja interna de pêlos das antenas dos machos densa e constituída por pêlos avermelhados. Equador. .......... ............... H. endyba Galileo \& Martins, 2004

Pronoto preto com faixas de pubescência amarelada; flagelômeros unicolores; franja interna de pêlos das antenas, em ambos os sexos, constituída por pêlos pretos e mais esparsos.... . 2

2(1). Partes laterais do protórax com faixa preta oblíqua e larga; faixa de pubescência branca no meio dos metepimeros continuada pelos lados do metasterno; flagelômeros pretoavermelhados....... H. yandaira Galileo \& Martins, 2004

Partes laterais do protórax inteiramente recobertas por pubescência amarelada; lados do metasterno com área grande coberta por pubescência amarelada que vai até as metacoxas; flagelômeros amarelados.........................

3(2). Élitros com única faixa de pubescência amarelada, transversal, ligeiramente recurva, atrás do meio. Bolívia. .... ................ H. ybyra Galileo \& Martins, 2004

Metade apical dos élitros com três faixas de pubescência amarelada, transversais: uma ligeiramente recurva atrás do meio, a segunda perpendicular à sutura no quarto apical, a terceira curva em sentido oposto ao da primeira no sexto apical. Fig. 6. Brasil (Amazonas).................. ............. Hena Martins \& Galileo sp. nov.

\section{AGRADECIMENTOS}

Marcela L. Monné pela identificação dos Torneutini; ao Rafael dos Santos Araújo pela execução das fotografias de Lamiinae. Aos participantes das coletas na torre da ZF-2, Catarina da Silva Motta, Simone Trovisco, Francisco Felipe Xavier Filho, Alexandre da Silva Filho, Joseleide Teixeira Câmara, Marcelo Cutrim Moreira de Castro, Fábio Godoi, Fabrício Báccaro, Luis de Sales Aquino e Alexandre Ururahy Rodrigues, funcionários ou alunos do INPA.

\section{BIBLIOGRAFIA CITADA}

Aurivillius, C. 1891. Neue Coleoptera Longicornia. Entomologisk Tidskrift, 12: 97-106.

Aurivillius, C. 1902. Neue oder wenig bekannte Coleoptera Longicornia. 7. Entomologisk Tidskrift, 23: 207-224, 9 figs.

Aurivillius, C. 1908. Cerambyciden aus den Granzgebieten zwischen Peru und Bolivien gesammelt von Dr. Nils Holmgren. Arkive för Zoologi, 5(1): 1-13.

Aurivillius, C. 1921. Neue Cerambyciden aus der Sammlung G. van Roon. Tijdschrift voor Entomologie, 64: 46-53.

Bates, H. W. 1861. Contributions to an insect fauna of the Amazon Valley. Coleoptera: Longicornes. The Annals and Magazine of Natural History, (3)8: 40-52, 147-152, 212-219, 471-478.

Bates, H. W. 1862. Contributions to an insect fauna of the Amazon Valley. Coleoptera: Longicornes. The Annals and Magazine of Natural History, (3)9: 117-124, 396-405, 446-458. 


\section{ACTA

Bates, H. W. 1863. Contributions to an insect fauna of the Amazon Valley. Coleoptera: Longicornes. The Annals and Magazine of Natural History, (3)12: 100-109, 275-288, 367-381.

Bates, H. W. 1864. Contributions to an insect fauna of the Amazon Valley. Coleoptera: Longicornes. The Annals and Magazine of Natural History, (3)13: 43-56, 144-164; 14: 11-24.

Bates, H. W. 1865. Contributions to an insect fauna of the Amazon Valley. Coleoptera: Longicornes. The Annals and Magazine of Natural History, (3)15: 213-225, 382-394; 16: 101-113, 167$182,308-314$.

Bates, H. W. 1866. Contributions to an insect fauna of the Amazon Valley. Coleoptera: Longicornes. The Annals and Magazine of Natural History, (3) 17: 31-42, 191-202, 288-303, 367-373, 425435.

Bates, H. W. 1867. New genera of longicorn Coleoptera from the River Amazons. The Entomologist's Monthly Magazine, 4: 22-28.

Bates, H. W. 1869. Contribution to an insect fauna of the Amazon Valley (Coleoptera: Cerambycidae). The Transactions of the Entomological Society of London 1869: 37-58.

Bates, H. W. 1870. Contribution to an insect fauna of the Amazon Valley (Coleoptera: Cerambycidae The Transactions of the Entomological Society of London 1870: 243-335, 391-444.

Carneiro, V. M. C. 2004. Composição florística e análise estrutural de floresta primária de terra firme na bacia do rio Cuieiras, Manaus$A M$. Dissertação de mestrado. Manaus, Instituto Nacional de Pesquisas da Amazônia/Fundação Universidade do Amazonas, $\mathrm{X}+67 \mathrm{pp}$.

Dillon, L. S.; Dillon, E. S. 1946. The tribe Onciderini. Part II. Scientific Publications Reading Public Museum and Art Gallery, 6: 189-413.

Erichson, W. F. 1847. Conspectus insectorum coleopterorum quae in Republica Peruana observata sunt. Archiv für Naturgeschichte, 13: 67-185.
Galileo, M. H. M.; Martins, U. R. 2004. Novos táxons em Hemilophini (Coleoptera, Cerambycidae) com única carena umeral. Iheringia, Série Zoologia, Porto Alegre, 94(4):381388.

Martins, U. R.; Galileo, M. H. M. 2004. Cerambycidae (Coleoptera) coletados na Venezuela na copa de Matayba (Sapindaceae) e Vochysia (Vochysiaceae). Revista Brasileira de Entomologia, 48(2): 229-232.

Monné, M. A. 1978. O gênero Lepturges (s. str.) Bates, 1863, no Norte e Centro-Oeste do Brasil (Coleoptera, Cerambycidae, Lamiinae, Acanthocinini). Revista Brasileira de Biologia, 38(1): $1-12$.

Monné, M. A. 1994. Catalogue of the Cerambycidae (Coleoptera) of the Western Hemisphere. Part XV. São Paulo, Sociedade Brasileira de Entomologia, 107 pp.

Monné, M. A. 2001. Gênero Plistonax Thomson, 1864 (Coleoptera, Cerambycidae, Lamiinae, Acanthoderini): espécie nova e chave de identificação. Boletim do Museu Nacional, 466: 1-3.

Santos-Silva, A.; Martins, U. R. 2003. Revisão do gênero Physopleurus Lacordaire, 1869 e notas em Macrotomini (Coleoptera, Cerambycidae, Prioninae). Revista Brasileira de Entomologia, 47(2): 245-265.

White, A. 1853. Catalogue of the coleopterous insects in the collection of the British Museum. Longicornia 1. London, British Museum, 7: 1-174, pls 1-4.

White, A. 1855. Catalogue of the coleopterous insects in the collection of the British Museum. Longicornia 2. London, British Museum, 8: 175-412, pls 5-10.

Recebido em 22/08/2005

Aceito em 04/04/2006 